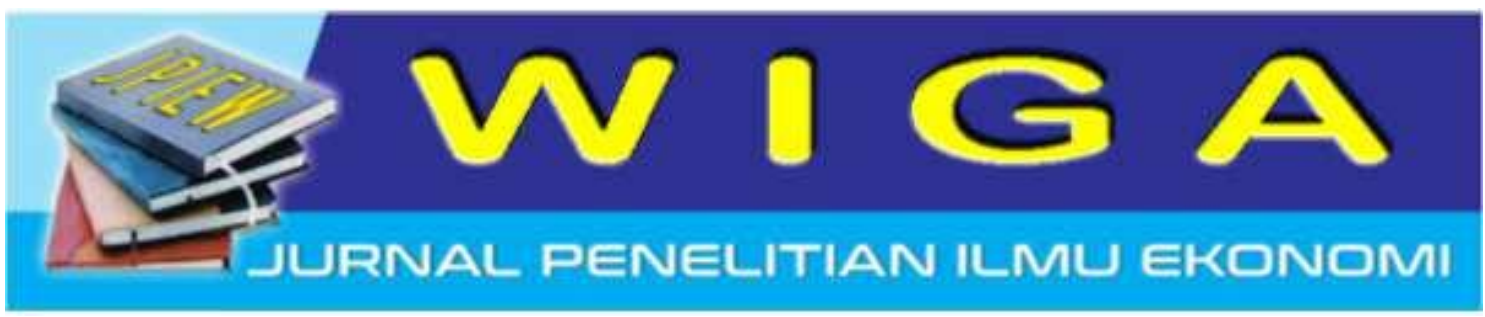

\title{
Optimalisasi Organizational Citizenship Behavior (OCB) Pada Pegawai Dinas Di Kabupaten Lumajang
}

\author{
Sukma Irdiana ${ }^{1)}$, Kusnanto Darmawan ${ }^{2)}$ \\ STIE Widya Gama Lumajang \\ Email.sukmapasah@gmail.com
}

\begin{abstract}
Abstrak
Penelitian ini bertujuan untuk mengetahui pengaruh kepuasan kerja, komitmen organisasi dan budaya organisasi secara parsial dan simultan terhadap organizational citizenship behavior $(O C B)$ pada pegawai dinas di Kabupaten Lumajang. Jenis penelitian yang digunakan adalah deskriptif dengan pendekatan asosiatif kausal. Penelitian ini dilakukan dengan jumlah responden sebanyak 147 orang. Teknik pengambilan sampel yang digunakan adalah teknik sampling jenuh. Pengujian hipotesis dilakukan dengan analisis regresi linier berganda untuk hipotesis melalui program SPSS 16 for windows. Berdasarkan hasil penelitian di peroleh bahwa kepuasan pegawai dan budaya organisasi terdapat pengaruh positif signifikan secara parsial terhadap organizational citizenship behavior $(O C B)$ pada pegawai dinas di Kabupaten Lumajang. Sedangkan komitmen organisasi tidak terdapat pengaruh positif signifikan secara parsial terhadap organizational citizenship behavior $(O C B)$ pada pegawai dinas di Kabupaten Lumajang. Secara simultan kepuasan pegawai, komitmen organisasi dan budaya organisasi terdapat pengaruh positif signifikan secara simultan terhadap organizational citizenship behavior $(O C B)$ pada pegawai dinas di Kabupaten Lumajang. Variable yang diteliti berpengaruh sebesar 63,3\% terhadap organizational citizenship behavior (OCB) dan sisanya dipengaruhi oleh variable lain yang tidak di teliti.
\end{abstract}

Kata kunci : kepuasan pegawai, komitmen organisasi, budaya organisasi dan organizational citizenship behavior $(\mathrm{OCB})$.

\begin{abstract}
This study aims to determine the effect of job satisfaction, organizational commitment and organizational culture partially and simultaneously to organizational citizenship behavior (OCB) on official staff in Lumajang District. The research type used is descriptive with causal associative approach. This study was conducted with the number of respondents as many as 147 people. The sampling technique used is a saturated sampling technique. Hypothesis testing is done by multiple linear regression analysis for hypothesis through SPSS 16 for windows program. Based on the results of the study obtained that the satisfaction of
\end{abstract}


employees and organizational culture there is a significant positive influence partially on organizational citizenship behavior $(O C B)$ on the official staff in Lumajang District. While organizational commitment there is no significant positive effect partially on organizational citizenship behavior (OCB) on official employees in Lumajang District. Simultaneously employee satisfaction, organizational commitment and organizational culture there is a significant positive influence simultaneously to organizational citizenship behavior $(O C B)$ on official staff in Lumajang District. The variables studied have an effect of $63.3 \%$ on the organizational citizenship behavior $(O C B)$ and the rest is influenced by other variables that are not in carefully.

Keywords: employee satisfaction, organizational commitment, organizational culture and organizational citizenship behavior $(O C B)$.

\section{PENDAHULUAN}

Instansi pemerintah pada era sekarang dituntut untuk memperhatikan sumber daya manusia, sebagai elemen penting yang berpengaruh terhadap keefektifan kerja organisasi, terutama dalam jangka panjang. Hal ini dilakukan sebagai salah satu upaya pemerintah dalam pengelolaan sumber daya manusia. secara baik untuk mengefektifkan kerja organisasi, yang dapat terlihat dari pembagian kerja, hubungan pekerjaan antara unit-unit dan sub sistem. Kondisi semacam ini diharapkan dapat menciptakan kerjasama tim setiap unit kerja dalam organisasi. Kerjasama tim yang kuat mampu mendorong karyawan berperilaku positif terhadap rekan kerja salah satunya adalah perilaku organisasi kewarganegaraan.

Kepuasan kerja adalah salah satu unsur yang dapat mempengaruhi perilaku organisasi kewarganegaraan. Menurut Handoko (2002), kepuasan kerja adalah keadaan emosional yang menyenangkan atau tidak menyenangkan dengan mana para karyawan memandang pekerjaan mereka. Kepuasan kerja merupakan cermin perasaan seseorang terhadap pekerjaanya. Kepuasan kerja adalah bentuk perasaan dan ekspresi seseorang ketika dia mampu/tidak mampu memenuhi harapan dari proses kerja dan kinerjanya. Timbul dari proses transformasi emosi dan pikiran dirinya yang melahirkan sikap atau nilai terhadap sesuatu yang dikerjakan dan diperolehnya, dalam dunia lingkungan kerja. Beragam ekspresi karyawan, mulai tersenyum, tertawa, mengeluh, akrab dengan sesama mitra kerja, mengisolasi diri, dan berekspresi emosional seperti : marah atau kurang bersahabat dengan lingkungan kerja. Salah satu faktor penyebab kondisi tersebut adalah perbedaan derajat kepuasan kerja. Semakin tinggi derajat kepuasan kerja, semakin bersahabat sang karyawan dengan lingkungan kerja.

Faktor lain yang berdampak positif terhadap perilaku karyawan bagi perusahaan adalah komitmen. Bagi suatu organisasi komitmen merupakan unsur yang dapat mempengaruhi perilaku organisasi kewarganegaraan. Menurut Soekidjan (2009), Komitmen adalah kemampuan dan kemauan untuk menyelaraskan perilaku pribadi dengan kebutuhan, prioritas dan tujuan organisasi, mencakup cara-cara mengembangkan tujuan atau memenuhi kebutuhan organisasi, yang intinya mendahulukan misi organisasi dari pada kepentingan pribadi. Komitmen adalah sebuah keadaan psikologi karyawan untuk tetap bertahan dalam organisasi. Beberapa organisasi memasukkan unsur komitmen sebagai salah satu syarat untuk memegang suatu jabatan atau posisi tertentu dalam kualifikasi pekerjaan. Permasalahan yang 
terjadi adalah banyak pengusaha maupun pegawai yang belum memahami arti komitmen yang sebenarnya. Pemahaman tersebut sangat penting agar tercipta kondisi kerja yang kondusif sehingga perusahaan dapat berjalan secara efisien dan efektif.

Budaya organisasi yang merupakan unsur yang mempengaruhi perilaku organisasi kewarganegaraan. Budaya organisasi merupakan suatu persepsi bersama yang dianut oleh anggota-anggota organisasi itu atau sistem makna bersama yang dihargai oleh organisasi (Robbins, 2006). Budaya yang dimiliki organisasi, perilaku karyawan dalam organisasi otomatis akan menyesuaikan dengan nilainilai yang digunakan perusahaan. Dampaknya saat karyawan menyatu dengan budaya perusahaan, maka karyawan akan menunjukkan sikap positif baik terhadap perusahaan maupun dengan rekan kerja.

Sumber daya manusia tidak hanya memiliki skill dan kualitas yang baik tetapi memiliki perilaku ekstra dimana salah satunya adalah perilaku organisasi kewarganegaraan. Perilaku extra-role misalnya : membantu rekan kerja menyelesaikan tugas, kesungguhan dalam mengikuti rapat-rapat organisasi, sedikit mengeluh banyak bekerja dan lain-lain. Pada saat pimpinan melakukan evaluasi kinerja terhadap pegawai, yang dievaluasi bukan hanya perilaku intra-role, tetapi perilaku extra-role menjadi bagian dari evaluasi karena perilaku extra-role memiliki kontribusi yang penting dengan perilaku intra-role.

Berdasarkan uraian diatas maka perumusan masalah penelitian ini adalah "Bagaimana pengaruh Kepuasan Kerja, Komitmen dan Budaya Organisasi secara parsial dan simultan terhadap Organizational Citizenship Behavior $(O C B)$ pada Pegawai Dinas Di Kabupaten Lumajang ?. Sedangkan tujuan penelitian ini adalah Untuk mengetahui pengaruh Kepuasan Kerja, Komitmen dan Budaya Organisasi secara parsial dan simultan terhadap Organizational Citizenship Behavior (OCB) pada Pegawai Dinas Di Kabupaten Lumajang.

\section{KAJIAN LITERATUR Kepuasan Kerja}

Menurut Robbins (2008) istilah kepuasan kerja merujuk kepada sikap umum seorang individu terhadap pekerjaan yang dilakukannya. Seseorang dengan tingkat kepuasan kerja tinggi menunjukkan sikap yang positif terhadap kerja itu, sedangkan seseorang yang tidak puas dengan pekerjaannya menunjukkan sikap yang negatif terhadap pekerjaan itu. Menurut Marihot T. E. Hariandja (2005:291), faktor yang mempengaruhi kepuasan kerja adalah gaji, pekerjaan itu sendiri, rekan kerja, atasan, promosi, dan lingkungan kerja.

\section{Komitmen Organisasi}

Komitmen organisasi menurut Gibson (1997) adalah identifikasi rasa, keterlibatan loyalitas yang ditampakkan pekerja terhadap organisasi atau unit organisasi. Komitmen ditunjukkan dalam sikap penerimaan, keyakinan yang kuat terhadap nilai- nilai dan tujuan organisasi, dan adanya dorongan yang kuat untuk mempertahankan keanggotaan dalam organisasi demi tercapainya tujuan organisasi. Menurut Minner dalam (Sopiah, 2008) mengemukakan empat faktor yang mempengaruhi komitmen karyawan antara lain faktor personal, karakteristik pekerjaan, karakteristik struktural, dan pengalaman kerja.

\section{Budaya Organisasi}

Budaya organisasi menurut Schein (2004) adalah sebagai pola asumsi dasar bersama yang telah dipelajari oleh anggota kelompok selama memecahkan masalah 
dalam beradaptasi eksternal dan integrasi internal, yang telah bekerja cukup baik untuk dianggap sah dan oleh karena itu untuk diajarkan terus-menerus sebagai cara memandang, berpikir, merasakan dan bertindak yang benar. Menurut Robbins \& Coulter (2012:52), ada 7 dimensi budaya organisasi yaitu inovasi dan keberanian mengambil risiko, perhatian terhadap detail (Attention to detail), berorientasi kepada hasil (Outcome orientation), berorientasi kepada manusia (People orientation), berorientasi tim (Team orientation), sikap agresif (Aggressivenes), dan Stabilitas (Stability).

\section{Organizational Citizenship Behavior $(\mathrm{OCB})$}

Menurut Organ dalam (Mohammad, 2011) menyatakan bahwa Organizational Citizenship Behavior (OCB) is an individual behavior that is discretionary, not directly or explicitly recognized by the formal reward system, and in the aggregate promotes the efficient and effective functioning of the organization. Organizational Citizenship Behavior $(O C B)$ didefinisikan sebagai pekerjaan yang berhubungan dengan perilaku yang tidak mengikat, tidak berkaitan dengan sistem reward formal yang organisasi, dan secara keseluruhan meningkatkan efektivitas fungsi organisasi. Lima Dimensi dalam Organizational Citizenship Behavior menurut Organ, Podsakoff, \& MacKenzie (2006) : Altruism, Civic virtue, Conscientiousness, Courtesy, dan Sportsmanship.

\section{METODE PENELITIAN}

Penelitian ini menggunakan penelitian kuantitatif dengan mencari hubungan assosiatif yang bersifat kausal. Menurut Sugiyono (2013:11), "Penelitian assosiatif merupakan penelitian yang bertujuan untuk mengetahui hubungan dua variabel atau lebih". Sedangkan kausal adalah hubungan sebab akibat. Dalam penelitian ini populasinya adalah semua pegawai di lima dinas di Kabupaten Lumajang. Teknik pengambilan sampel yang digunakan dalam penelitian ini diambil Non Probability Sampling. "Non Probability Sampling merupakan pengambilan sampel yang tidak memberi peluang/kesempatan sama bagi setiap unsur atau anggota populasi untuk dipilih menjadi sampel" (Sugiyono, 2014:218). Dan teknik yang dipilih yaitu Sampling jenuh. "Sampling jenuh adalah teknik penentuan sampel bila semua anggota populasi digunakan sebagai sampel” (Sugiyono, 2015:126).

\section{Teknik Analisis Data}

Sesuai dengan hipotesis dan tujuan yang ingin dicapai dalam penelitian, maka digunakan analisis regresi linier berganda dengan bentuk hubungan assosiatif kausal, yang digunakan untuk mengetahui pengaruh variabel independen dalam memprediksi variabel dependen dalam penelitian ini (Sugiyono, 2013:169). Sebelum melakukan analisis dan uji pengaruh, maka terhadap kuesioner perlu dilakukan uji validitas dan reliabilitas. Selanjutnya akan dilakukan analisis dan uji pengaruh yang menggunakan asumsi dasar regresi linier berganda bahwa data harus berdistribusi normal.

\section{Pengujian Hipotesis}

Setelah dilakukan analisis regresi linier berganda kemudian dilakukan pengujian hipotesis yaitu uji t (uji parsial) dan uji $\mathrm{F}$ (uji simultan) yang digunakan untuk mengetahui apakah ada pengaruh antara variabel independen (kepuasan pegawai, komitmen organisasi dan budaya organisasi) terhadap variabel dependen (Organizational Citizenship Behavior $(O C B))$. Serta manakah diantara variabel independen yang mempunyai dominan terhadap variabel dependen. Selanjutnya dilakukan Uji Koefisien Determinasi $\left(\mathrm{R}^{2}\right)$ 
yang digunakan untuk mengetahui tingkat ketepatan yang paling baik dalam analisa regresi. Tingkat ketepan dalam koefisien determinasi itu biasanya dinyatakan dalam prosentase.

\section{HASIL DAN PEMBAHASAN}

Hasil uji asumsi klasik yang terkait dengan uji normalitas menunjukkan bahwa data yang digunakan dalam penelitian ini untuk variabel kepuasan kerja, komitmen organisasi, budaya organisasi dan organizational citizenship behavior adalah normal. Dengan demikian, asumsi normalitas dapat dipenuhi. Begitu juga asumsi multikolinieritas, hasil pengujian menunjukkan bahwa semua variabel yang digunakan sebagai prediktor model regresi menunjukkan nilai VIF yang cukup kecil, dimana semuanya berada di bawah 10 dan nilai tollerance lebih dari 0,1 . Hal ini berarti bahwa variabel bebas yang digunakan dalam penelitian tidak menunjukkan adanya gejala multikolinieritas, yang berarti bahwa semua variabel independen dalam penelitian ini adalah variabel yang saling independen. Hasil uji heteroskedastisitas dengan scatterplot menunjukkan tidak ada pola yang jelas dan titik-titik menyebar di atas dan di bawah angka 0 pada sumbu Y, sehingga dapat disimpulkan tidak terjadi heterokedastisitas. Dengan demikian seluruh asumsi klasik dapat dipenuhi.

\section{Analisis Regresi Linier Berganda}

Hasil analisis regresi berganda dapat dilihat pada tabel 1 berikut ini :

\section{Tabel 1. Analisis Regresi Linier Berganda}

Coefficients $^{\mathrm{a}}$

\begin{tabular}{|c|c|c|c|c|c|c|c|c|}
\hline & & \multicolumn{2}{|c|}{$\begin{array}{l}\text { Unstandardized } \\
\text { Coefficients }\end{array}$} & \multirow{2}{*}{\begin{tabular}{|c} 
Standardized \\
Coefficients
\end{tabular}} & \multirow[b]{2}{*}{$\mathrm{T}$} & \multirow[b]{2}{*}{ Sig. } & \multicolumn{2}{|c|}{$\begin{array}{c}\text { Collinearity } \\
\text { Statistics }\end{array}$} \\
\hline \multicolumn{2}{|c|}{ Model } & B & Std. Error & & & & Tolerance & VIF \\
\hline \multirow[t]{4}{*}{1} & (Constant) & .082 & 1.399 & & .059 & .953 & & \\
\hline & $\begin{array}{l}\text { KEPUASAN } \\
\text { KERJA }\end{array}$ & .137 & .045 & .175 & 3.046 & .003 & .779 & 1.284 \\
\hline & KOMITMEN & .045 & .082 & .030 & .547 & .585 & .828 & 1.207 \\
\hline & BUDAYA & .575 & .045 & .702 & 12.672 & .000 & .835 & 1.198 \\
\hline
\end{tabular}

a. Dependent Variable: OCB

Sumber : Hasil Pengolahan Data Kuesioner dengan SPSS 2018

Dari perhitungan regresi linier berganda dengan menggunakan program SPSS forwindows maka didapat hasil sebagai berikut :

\section{$\mathrm{Y}=\mathbf{0 , 0 8 2 + 0 , 1 3 7 X 1 + 0 , 0 4 5 X 2 + 0 , 5 7 5 X 3}$}

Dari persamaan tersebut diatas dapat dijelaskan :

- Dalam persamaan koefisien regresi diatas, konstanta (Bo) adalah sebesar 0,082 hal ini berarti jika tidak ada perubahan variabel kepuasan pegawai, komitmen organisasi dan budaya organisasi tetap sebesar 0,082.

- Nilai koefisien regresi kepuasan pegawai diperoleh sebesar 0,137 . hal ini berarti bahwa apabila kepuasan pegawai naik $1 \%$ maka akan menaikan Organizational Citizenship Behavior $(O C B)$ sebesar 0,137 atau sebaliknya. 
- Nilai koefisien regresi variabel komitmen organisasi diperoleh sebesar 0,045 , hal ini berarti bahwa setiap terjadi kenaikan pada komitmen organisasi sebesar $1 \%$ maka akan menaikkan Organizational Citizenship Behavior (OCB) sebesar 0,045 atau sebaliknya.

- Nilai koefisien regresi variabel budaya organisasi diperoleh sebesar 0,575 hal ini berarti bahwa apabila budaya organisasi naik $1 \%$ maka akan menaikan Organizational Citizenship Behavior (OCB) sebesar 0,575 atau sebaliknya.

\section{Hasil Uji Hipotesis \\ Uji t (Uji Parsial)}

Secara parsial, yang dapat dilihat dari besarnya $\mathrm{t}$ hitung terhadap $\mathrm{t}$ tabel dengan uji 2 sisi. Dalam penelitian ini diketahui bahwa $\mathrm{n}=147$ pada tingkat signifikan $5 \%$. Pada tingkat kesalahan $(\alpha=0,05)$ dengan menggunakan uji 2 sisi diperoleh nilai $t$ tabel sebesar 1,99167. Sedangkan t hitung dari Kepuasan Kerja, Komitmen dan Budaya Organisasi terhadap Organizational Citizenship Behavior $(O C B)$ pada Pegawai Dinas Di Kabupaten Lumajang dapat dilihat pada tabel 1.
Hasil pada tabel 1diatas dapat dijelaskan sebagai berikut :

- Untuk variabel kepuasan pegawai nilai t hitung sebesar 3,046 > nilai t table sebesar 1,97646 dengan tingkat signifikasi lebih dari 0,05 yaitu 0,003 . Maka Ha diterima, jadi variabel kepuasan pegawai berpengaruh signifikan terhadap Organizational Citizenship Behavior (OCB).

- Untuk variabel komitmen organisasi nilai t hitung sebesar $0,547<$ nilai $t$ table sebesar 1,97646 dengan tingkat signifikasi lebih dari 0,05 yaitu 0,585 . Maka Ho diterima, jadi variabel komitmen organisasi tidak berpengaruh signifikan terhadap Organizational Citizenship Behavior $(O C B)$.

- Untuk variabel budaya organisasi nilai t hitung sebesar 12,672 > nilai $t$ table sebesar 1,97646 dengan tingkat signifikasi lebih dari 0,05 yaitu 0.000 . Maka Ha diterima, jadi variabel budaya organisasi berpengaruh signifikan terhadap Organizational Citizenship Behavior (OCB).

\section{Uji F (Uji Simultan)}

Hasil analisis regresi berganda simultan dapat dilihat pada tabel 2 sebagai berikut :

Tabel 2. Hasil Uji F (Uji Simultan)

\begin{tabular}{|ll|r|r|r|c|c|}
\hline \multicolumn{7}{|c|}{ ANOVA $^{\text {b }}$} \\
\hline 1 & Sum of Squares & \multicolumn{1}{c|}{ df } & Mean Square & F & Sig. \\
\hline & Regression & 357.148 & 3 & 119.049 & 82.247 & $.000^{\mathrm{a}}$ \\
& Residual & 206.988 & 143 & 1.447 & & \\
Total & 564.136 & 146 & & & \\
\hline
\end{tabular}

a. Predictors: (Constant), BUDAYA, KOMITMEN, KEPUASAN KERJA

b. Dependent Variable: OCB

Sumber : Hasil Pengolahan Data Kuesioner dengan SPSS 2018

Secara simultan, dengan tingkat signifikan $5 \%$ dan derajat kebebasan df1 =
3 dan df2 $=147$ maka didapat Ftabel $=$ 2,67. Dalam perhitungan diperoleh nilai $\mathrm{F}$ 
hitung lebih besar dari F tabel, yaitu 82,247 $>$ 2,67 sehingga Ho ditolak. Sedangkan jika dilihat dari nilai signifikan hitung adalah 0,000 yaitu $<0,05$ maka keputusannya juga menolak Ho yang berarti bahwa secara simultan terdapat pengaruh Kepuasan Kerja, Komitmen dan Budaya Organisasi secara simultan terhadap Organizational Citizenship Behavior (OCB) pada Pegawai Dinas Di Kabupaten Lumajang.

Hasil Koefisien Determinasi (R2)

Hasil koefisien determinasi (R2) dapat dilihat pada tabel 3 adalah sebagai berikut

Tabel 3. Koefisien Determinasi

Model Summary ${ }^{b}$

\begin{tabular}{|l|r|r|r|r|}
\hline Model & $\mathrm{R}$ & \multicolumn{1}{c|}{ R Square } & Adjusted R Square & $\begin{array}{c}\text { Std. Error of the } \\
\text { Estimate }\end{array}$ \\
\hline 1 & $.796^{\mathrm{a}}$ & .633 & .625 & 1.20311 \\
\hline
\end{tabular}

a. Predictors: (Constant), BUDAYA, KOMITMEN, KEPUASAN KERJA

b. Dependent Variable: OCB

Sumber : Hasil Pengolahan Data Kuesioner dengan SPSS 2018

Hasil analisis regresi linier berganda tersebut dapat terlihat dari $\mathrm{R}$ Square sebesar 0,633 atau $63,3 \%$ yang menunjukkan bahwa Organizational Citizenship Behavior (OCB) dipengaruhi oleh ketiga variabel yaitu Kepuasan Kerja, Komitmen dan Budaya Organisasi. Sedangkan sisanya yaitu $36,7 \%$ Organizational Citizenship Behavior $(O C B)$ dipengaruhi variabel lain yang belum diteliti dalam penelitian ini.

\section{PEMBAHASAN}

\section{Kepuasan Pegawai Terhadap Organizational Citizenship Behavior (OCB)}

Hasil dari penelitian ini menunjukan bahwa para pegawai yang mendapatkan kepuasan kerja, akan menunjukan rasa sukarela mereka untuk melakukan pekerjan diluar deskripsi pekerjaanya. Adanya kesesuaian antara gaji dengan sesuai beban kerja, bekerja dengan penuh tanggung jawab, mengerjakan pekerjaan dengan baik akan dipromosikan, diperlakukan dengan baik oleh pemimpin atau atasan dan juga menikmati bekerja dengan teman-teman dalam lingkungan kerja akan meningkatkan perilaku organisasi kewarganegaraan pada pegawai.

\section{Komitmen Organisasi Terhadap Organizational Citizenship Behavior $(\mathrm{OCB})$}

Hasil penelitian ini mengindikasikan bahwa para pegawai yang tidak merasa bangga terhadap dinas dikarenakan perputaran atau rotasi perpindahan karyawan membuat para pegawai kurang komitmen terhadap dinas, selain itu pegawai tidak memiliki kekhawatiran akan resiko yang diterima jika mereka meninggalkan dinas dan pegawai percaya bahwa perputaran atau rotasi itu adalah hal biasa sehingga dimanapun mereka berada, pegawai harus siap untuk bekerja. Perilaku organisasi kewarganegaraan yang meningkat ditandai dengan niat membantu rekan sekerja dengan sukarela, patuh terhadap peraturan pegawai negeri sipil, tidak memberikan isu-isu yang dapat menjatuhkan karyawan lain, membatu meringankan masalah-masalah yang 
dihadapi sesama pegawai dan mendukung fungsi-fungsi kedinasan secara profesional. Perilaku organisasi kewarganegaraan para pegawai dapat ditingkatkan dengan cara meningkatkan intensitas penerapan komitmen organisasional pegawai kedinasan.

\section{Budaya Organisasi Terhadap Organizational Citizenship Behavior $(\mathrm{OCB})$}

Hasil penelitian ini mengindikasikan bahwa nilai-nilai yang terkandung dalam budaya organisasi yang meliputi budaya pemberian kesempatan kepada pegawai untuk lebih berperan aktif dalam kegiatan organisasi, konsistensi organisasi dalam menerapkan atiran organisasi, kemampuan organisasi dalam beradaptasi terhadap perkembangan yang terjadi di masyarakat serta adanya kejelasan arah, tujuan, sasaran dan prosedur kerja akan mampu memunculkan kerelaan para pegawai dalam melakukan pekerjaan-pekerjaan di luar deskripsi pekerjaan mereka. Perilaku organisasi kewarganegaraan pegawai yang meningkat ditandai dengan meningkatnya perilaku untuk membantu rekan kerja agar terhindar dari perselisihan, pengabdian atau dedikasi yang tinggi pada pekerjaan serta bertanggung jawab untuk terlibat, berpartisipasi dan peduli dalam berbagai kegiatan yang diselenggarakan organisasi.

\section{KESIMPULAN DAN SARAN}

Berdasarkan hasil penelitian dan pembahasan maka dapat disimpulkan beberapa hal sebagai berikut :

- Kepuasan pegawai berpengaruh positif terhadap Organizational Citizenship Behavior (OCB) pegawai. Semakin tinggi kepuasan pegawai yang dimiliki pada dinas Kabupaten Lumajang maka akan meningkatkan Organizational Citizenship Behavior (OCB) pegawai yang bertugas pada dinas Kabupaten Lumajang.
- Komitmen organisasi tidak berpengaruh positif terhadap Organizational Citizenship Behavior (OCB). Semakin tinggi komitmen organisasi yang dimiliki pegawai maka semakin rendah kemauan untuk berperan ekstra dalam melaksanakan tugasnya bagi para pegawai yang bertugas di dinas Kabupaten Lumajang.

- Budaya organisasi berpengaruh positif terhadap Organizational Citizenship Behavior (OCB) pegawai. Semakin tinggi nilai-nilai budaya yang dimiliki dan dikembangkan pada dinas Kabupaten Lumajang maka akan meningkatkan Organizational Citizenship Behavior (OCB) pegawai yang bertugas pada dinas Kabupaten Lumajang.

Berdasarkan kesimpulan di atas maka beberapa saran yang dapat dipergunakan sebagai bahan pertimbangan dalam menentukan kebijakan bagi dinas, di masa mendatang terutama yang berkaitan dengan kepuasan kerja, komitmen organisasional, budaya organisasi dan Organizational Citizenship Behavior (OCB). Dinas Kabupaten Lumajang sebaiknya dinas meningkatkan komitmen organisasi yang merupakan variable dari penelitian dengan cara memberlakukan dengan sungguhsungguh semua aturan yang ada di dalam dinas agar dapat meningkatkan kesadaran pegawai akan kewajibannya untuk loyal kepada dians, serta dinas juga berkewajiban memenuhi semua hak yang dimiliki pegawai agar pegawai puas terhadap tugas atau pekerjaan yang mereka emban atau kerjakan.

\section{REFERENSI}

Adam Ibrahim Indra Wijaya. 2000. Perilaku Organisasi. Jakarta: Sinar Baru Algesindo 
Gibson, Ivancevich, Donnely. 1997. Organisasi: Perilaku, Struktur, Proses. Jakarta: PT. Binarupa Aksara.

Handoko T. Hani. 2002. Manajemen Personalia dan Sumber Daya Manusia, Yogyakarta : BPFE.

Hariandja, Marihat Tua Efendi. 2005. Manajemen Sumber Daya Manusia. Jakarta:PT. Grasindo.

Organ, D.W. 1988. Organizational Citizenship Behavior: The Good Soldier Syndrome. Lexinton book. Lexington,MA

Robbins dan Judge. 2008.Perilaku Organisasi. Jakarta: Salemba Empat

Robbins, Stephen P. 2006. Perilaku Organisasi. Edisi Kesepuluh. PT. Indeks Jakarta

Robbins. Stephen P. Coulter. Mary. 2012. Management. Eleventh Edition. Jakarta: England.

Schein, Edgar H. 2004. Organizational Culture and Leadership. Third Edition. Jossey-Bass Publishers, San Francisco.

Steer, Richard M. 1980. Effectivitas Organisasi. Terjemah. Jakarta:Erlangga.

Soegiarto Soekidjan, Sp. Kj. (2009). Komitmen Organisasi Sudahkah menjadi Bagian Dari Kita.

Sopiah. 2008. Perilaku Organisasi. Yogyakarta:Andi.

Supranto, 2001, Pengukuran Tingkat Kepuasan Pelanggan untuk Menaikkan Pangsa Pasar, Penerbit Rineka Cipta, Jakarta, 230,243

Wahyuningsih, T., 2009, Pengaruh Komitmen Kerja Karyawan Terhadap Organizational Citizenship Behavior (OCB) Karyawan Pada Rumah Sakit Umum PKU Muhammadiyah Yogyakarta. 